\title{
KINETICS STUDIES ON THE TAUTOMERIC REACTION OF 4-AMINO-5-METHYL-2,4-DIHYDRO-3H-1,2,4- TRIAZOLE-3-THIONE IN THE GAS PHASE: DFT AND CBS-QB3 METHODS USING TRANSITION STATE THEORY
}

\author{
ZAHRA KAZEMINEJAD ${ }^{a}$, ABOLFAZL SHIROUDI I, ${ }^{b}$ KHALIL POURSHAMSIAN ${ }^{a,{ }^{*}}$, FARHAD HATAMJAFARI $^{a}$, \\ AHMAD REZA OLIAEY ${ }^{a}$ \\ ${ }^{a}$ Department of Chemistry, Tonekabon Branch, Islamic Azad University, Tonekabon, Iran \\ ${ }^{b}$ Young Researchers and Elite Club, East Tehran Branch, Islamic Azad University, Tehran, Iran
}

\begin{abstract}
The isomerization reactions of the 4-amino-5-methyl-2,4-dihydro-3H-1,2,4-triazole-3-thione have been studied theoretically using density functional theory (DFT) along with various exchange-correlation functionals (B3LYP and M06-2x) as well as the benchmark CBS-QB3 quantum chemical approach. The calculated energy profile has been supplemented with calculations of kinetic rate constants by means of transition state theory (TST).

Based on the optimized isomers geometries using the CBS-QB3 method, a natural bond orbital analysis reveals that the electronic delocalization from nonbonding lone-pair orbitals $\left[\mathrm{LP}(\mathrm{e})_{\mathrm{S} 7}\right]$ to the neighboring $\sigma^{*}{ }_{\mathrm{N} 2-\mathrm{C} 3}$ antibonding orbital increase from isomer $\mathbf{1}$ to isomer $\mathbf{2}$. Also, the LP(e) $\rightarrow \sigma^{*}{ }_{\mathrm{N} 2-\mathrm{C} 3}$ delocalizations could fairly explain the increase of occupancies of LP(e) non-bonding orbitals in the ring of isomers $\mathbf{1}$ and $\mathbf{2}(\mathbf{2}>\mathbf{1})$. The electronic delocalization from LP(e) non-bonding to $\sigma^{*}{ }_{\mathrm{N} 2-\mathrm{C} 3}$ antibonding orbitals increase the ground state structure stability, Therefore, the increase of LP(e) $\rightarrow \sigma_{\mathrm{S} 2-\mathrm{C} 3}$ delocalizations could fairly explain the kinetics of the isomerization reactions $\mathbf{1}$ and $\mathbf{2}\left(k_{2}>k_{1}\right)$. NBO results also suggest that the kinetics of these processes are controlled by LP $\rightarrow \sigma^{*}$ resonance energies.
\end{abstract}

Keywords: Isomerization, Rate constant, Reaction mechanism, Chemical kinetics, DFT, NBO.

\section{INTRODUCTION}

Triazoles are known as the isosters of Imidazoles, also Imidazoles are the prominent medicinal moieties in which the carbon atoms are isosterically replaced by nitrogen [1]. The chemistry involving triazoles has a vital role due to their industrial and medicinal characteristics in pharmaceutical industry [2,3]. In addition, 1,2,4-triazoles and their derivatives are the important compounds in medicinal chemistry. In fact, they are realized as effective heterocyclic compounds [4]. Having two vital and stable factors in metabolic non-degradation related to drug targets[5] and forming hydrogen bonds, triazoles are biologically considered active molecules as pharmacophores $[6,7]$. The pharmacological activities are recorded as anti-bacterial [8], anti-fungal [9], anti-viral [10], anti-convulsant [11,12], anti-inflammatory [13,14], anticancer $[15,16]$ and anti-depressant whereas 1,2,4-triazoles effect on central nervous system, they can be great drugs as stimulants and anxiolytics [15]. Thioureas are significant compounds which contained sulfur and nitrogen [17]. They are proved to be useful as drug substances [18-22]. Some urea derivatives including heterocyclic rings are oxadiazoles. Thiadiazoles, triazoles, an pyrazoles which they are well-known for their valuable antituberculosis, antibacterial, and anticonvulsant properties [24]. Thioureas can be strong inhibitors against corrosion of Steel, $\mathrm{Al}$, and $\mathrm{Cu}$. Also, they are extensively regarded as the antibacterial agent against know drugs [24].

For the sake of more quantitative insights into these reaction mechanisms, comparison will be made with the high-level composite CBS-QB3 ab initio approach [25-33], to determine which exchange-correlation functional gives the most accurate energy barriers and reaction energies. We have shown that DFT methods alone are insufficient for quantitatively investigating the potential energy surface of the reaction mechanisms and kinetics of oxidation processes given the inability of many popular DFT functionals to quantitatively describe non-bonded interactions and barrier heights. The aim of this work is to provide quantitative theoretical insights in the isomerization reactions that are shown in Scheme 1. We shall first use density functional theory (DFT) along with the B3LYP [34,35] and the M06-2x [36] exchange-correlation functionals in conjunction with aug-cc-pVTZ basis set [37], and then compare the calculated energy barriers and reaction energies with the CBS-QB3 results. Furthermore, kinetic rate constants measured in the high-pressure limit using transition state theory [38-44] under atmospheric condition.

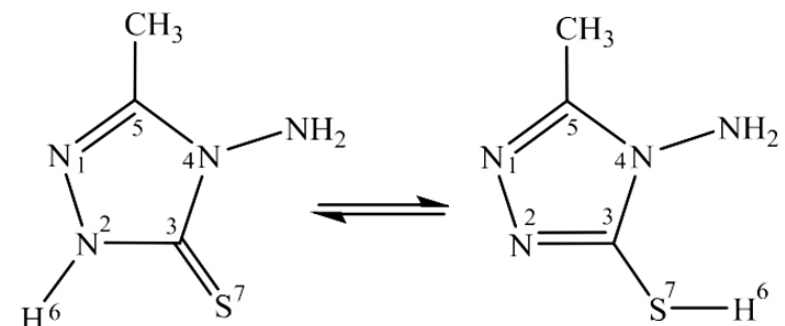

Isomer 1

Isomer 2

Scheme 1. The isomer structures of the 4-amino-5-methyl-2,4-dihydro3H-1,2,4-triazole-3-thione.

Finally, we will also try to supply further qualitative chemical insights into the involved reaction mechanisms by analyzing results achieved using bond order, donor-acceptor interaction energies and natural bond orbital (NBO) occupancies $[45,46]$

\section{COMPUTATIONAL DETAILS}

All electronic structure calculations were carried out by means of the Gaussian 09 software package [47]. Molecular structures were visualized with GaussView [48]. The molecular structures and harmonic vibrational frequencies of all stationary points were computed at the B3LYP/aug-cc-pVTZ and M06-2x/aug-cc-pVTZ levels of theory. M06- $2 x$ is the best DFT functional for thermochemistry and kinetics [49]. The nature of all optimized structures were determined according to the calculations of harmonic vibrational frequencies which were calculated at the same levels of theory to ensure that a minimum on the potential energy surface was obtained under the imposed constraint of the indicated symmetry. Energy minima possess the Hessian matrix with no negative eigenvalues, whereas transition state has one and only one negative eigenvalue corresponds to the motion of the atoms over a firstorder saddle point [50].

The energies of the all studied stationary points were re-evaluated by means of CBS-QB3 model. It includes low-level calculations on large basis sets, mid-sized sets for second-order correlation corrections, and small basis sets for high-level correlation corrections. The five step CBS-QB3 series of calculations start with a geometry optimization at the B3LYP/6-311G(2d,d,p) level, followed by a frequency calculation to obtain thermal corrections, zeropoint vibrational energy, and entropic information [51].

Geometry optimization of isomers $\mathbf{1}$ and $\mathbf{2}$ as well as transition state 
were performed with the Berny algorithm using the energy-represented direct inversion in the iterative subspace algorithm (GEDIIS) optimizer [50,52]. The intrinsic reaction coordinate (IRC) analysis [53] has been carried out in both directions (forward and backward) along the reaction path in order to check the energy profiles connecting the identified transition structure to the associated energy minima [54]. In the present work, TST calculations have been performed in conjunction with a detailed exploration of the IRC path at the B3LYP/6-31G ${ }^{* *}$ level of theory. 30 points on both the forward and reverse directions from the transition state position, IRCs in mass-weighted Cartesian coordinates were generated for each reaction with a $0.1 \mathrm{amu}^{1 / 2}$ Bohr step size in this work.

Rate constants and thermodynamic parameters of the isomerization reactions $\mathbf{1}$ and $\mathbf{2}$ were performed in the high-pressure limit using the implementation of canonical transition state theory (CTST) under atmospheric in the KiSThelP package [55]. Kinetic studies on the tautomeric reactions at $T=298 \mathrm{~K}$ is calculated using CTST is given by [56,57]:

$$
k_{\mathrm{TST}}(T)=\kappa(T) \times \frac{\sigma k_{\mathrm{B}} T}{h} \times \frac{Q_{T S}^{\dagger}}{Q_{\mathrm{R}}} \times \exp \left(-E^{\dagger} / k_{\mathrm{B}} T\right)
$$

where $k_{\mathrm{B}}$ and $h$ are the Boltzmann's and Planck's constants, $T$ is the absolute temperature, $\sigma$ is the reaction symmetry number, $\kappa(T)$ denotes the relevant tunneling correction factor, and $E^{\dagger}$ is the activation energy, defined as the difference between zero-point vibrational energies (ZPVE) of the transition state and the reactant. In the above equation, $Q^{\dagger}$ and $Q_{\mathrm{R}}$ represent the total molecular partition functions per unit volume for the transition state and the reactant, respectively. Rotational symmetry numbers are not included in the partition function and multiplied separately as reaction symmetry number in the calculation of the kinetic rate constants. Reaction symmetry number $\sigma=1$ is taken into consideration for the studied reactions according to the point groups of symmetries of the all stationary points. Kinetic rate constants are corrected by multiplying the TST rate constants in the Wigner [58,59] and Eckart $[60,61]$ tunneling correction factors. The Wigner tunneling correction is given by

$$
\kappa_{\text {wigner }}(T)=1+\frac{1}{24}\left(\frac{h \operatorname{Im}\left(v_{i}\right)}{k_{B} T}\right)^{2}
$$

where $\operatorname{Im}(u)$ is the imaginary vibrational frequency of the relevant transition state. Because of the simplicity of CTST, it gives the upper limit of the rate constant, and enables to provide reliable rate constants in the limiting high-pressure behavior. The unsymmetrical Eckart potential energy barrier is used to correct the theoretically determined TST rate constants by using Eckart tunneling correction as follows $[62,63]$

$$
\kappa_{\text {Eckart }}(T)=\frac{\exp \left(\Delta H_{\mathrm{f}}^{\dagger, 0 \mathrm{~K}} / k_{\mathrm{B}} T\right)}{k_{\mathrm{B}} T} \int_{0}^{\infty} p(E) \exp \left(-E / k_{\mathrm{B}} T\right) d E
$$

where $p(E)$ depends on $E$ and three other parameters which are determined by the shape of the barrier and an effective mass for the system [64], and $\Delta H^{\text {, }}$, is the zero-point corrected energy barrier in the forward direction.

\section{RESULTS AND DISCUSSION}

\section{Energetic and Thermodynamic Parameters}

Activation enthalpies $\left(\Delta H^{\dagger}\right)$, activation Gibbs free energies $\left(\Delta G^{\dagger}\right)$, and reaction energies $(\Delta H$ and $\Delta G)$ at $298 \mathrm{~K}$ for the isomerization reactions $\mathbf{1}$ and $\mathbf{2}$ are summarized in Table 1 . The different levels of theory calculations show that isomerization reaction $\mathbf{1}$ [isomer $1 \rightarrow$ isomer 2] is an endothermic process with reactions enthalpies $\left(\Delta H_{298 \mathrm{~K}}\right)$ ranging from 14 to $15 \mathrm{kcal} \mathrm{mol}^{-1}$ (Table 1 ), depending on the employed exchange-correlation functional. At pressure of 1 bar and room temperature, Gibbs free reaction energies $\Delta G$ s for reaction 2 [isomer $2 \rightarrow$ isomer 1] is negative, hence it is exergonic process while this parameter for reaction $\mathbf{1}$ is positive that is endogenic process. As can be seen from Table 1, activation enthalpies $\left(\Delta H^{\dagger}\right)$ and activation free energies $\left(\Delta G^{\dagger}\right)$ of the investigated pathways $\mathbf{1}$ and $\mathbf{2}$ are positive at $T=298 \mathrm{~K}$; therefore, the activation processes require energy and are not spontaneous. From the energy profiles supplied in Table 1, it appears that the production of the isomer 1 species via reaction $\mathbf{2}$ is the most favored reaction, since the isomerization reaction of the studied compound is strongly exergonic with Gibb's free activation energies $\left(\Delta G^{\circ}\right)$ ranging from -15.22 to $-13.44 \mathrm{kcal} \mathrm{mol}^{-1}$, and corresponding strongly exothermic processes $\left(\Delta H^{\circ \dagger}\right)$ with activation enthalpies ranging from -15.02 to $-14 \mathrm{kcal} \mathrm{mol}^{-1}$.

All DFT calculations (B3LYP and M06-2x) as well as CBS-QB3 composite method demonstrate that the activation energy barrier $\left(\Delta E^{\dagger}\right)$ characterizing the formation of isomer $20 \mathrm{~K}$ species is all in all lower by about $13.73-14.49 \mathrm{kcal}$ $\mathrm{mol}^{-1}$ than the barrier for the isomerization reaction 1. Similar observations can be made when Gibbs free activation energies are considered: in spite of slightly unfavorable entropies, the Gibb's free energy for the isomerization reaction $2\left(\sim 29.13-30.00 \mathrm{kcal} \mathrm{mol}^{-1}\right)$ is lower that for isomerization reaction 1 $\left(\sim 43.34-45.22 \mathrm{kcal} \mathrm{mol}^{-1}\right)$. Such differences in the obtained activation energies and Gibb's free activation energies for the studied pathways indicates that the formation of isomer 1 species will be kinetically favored over the formation of isomer 2 .

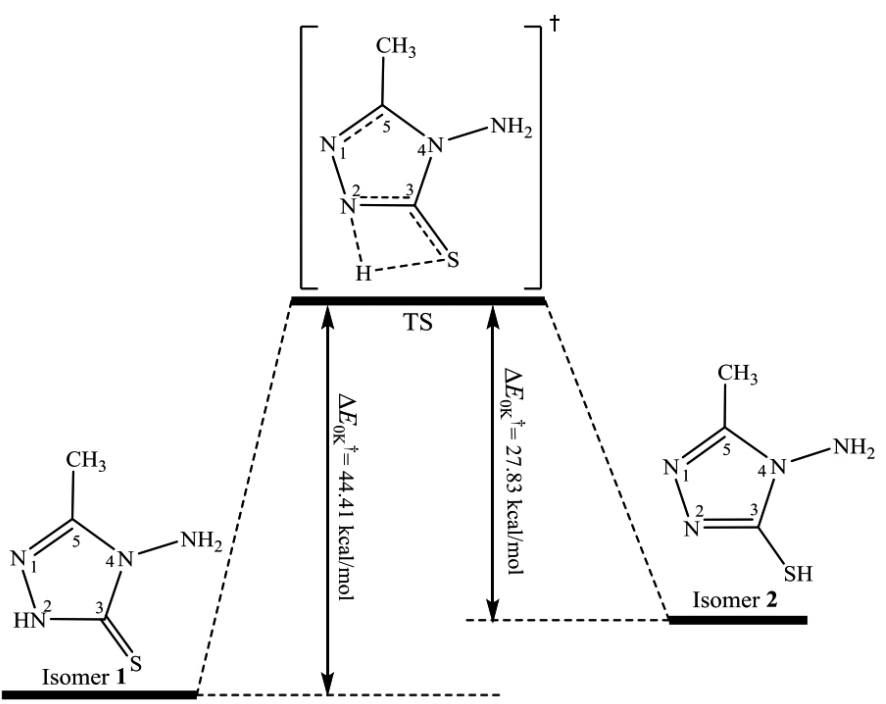

Fig.1. Energy profile for the isomerization reactions [isomer $1 \leftrightarrow$ isomer 2] at the CBS-QB3 level of theory

We note that the various exchange-correlation functionals which have been employed predict large differences in the relative energies of the identified stationary points, especially with regards to the extent of activation energies [65]. As was to be expected, because of the large self-interaction error, the B3LYP functional systematically yields strong underestimations of the computed activation energies for the studied reactions, up to $14.8 \mathrm{kcal} \mathrm{mol}^{-1}$, compared with the results obtained with the M06-2x functional, which most generally do not differ by more than $1.35 \mathrm{kcal} \mathrm{mol}^{-1}$.

In all calculations a scaling factors of $0.968,0.971$ and 0.99 were imposed on the calculated frequencies at the B3LYP/aug-cc-PVTZ, M06-2x/aug-ccpVTZ, and CBS-QB3 levels of theory, respectively [66,67]. The reader is referred to Fig. 1 and Table 1 for the relative activation parameters (enthalpies and Gibbs free energies) of the isomerization reactions at a pressure of $1.0 \mathrm{bar}$ and at room temperature.

\section{Structural characteristics of stationary points}

The geometrical characteristics of the reactants $(\mathbf{R})$, transition states (TS) and products $(\mathbf{P})$ of the studied reactions are supplied at the all theoretical levels in Table 2 and are shown in Fig. 2. Atom numbers are illustrated in Scheme 1 for clarity. The TS structure for the isomerization of 4- amino-5methyl-2,4-dihydro-3H-1,2,4-triazole-3-thione via isomerization reaction 2 is a four-membered cyclic structure. The most significant geometrical change is observed for the $\mathrm{N}_{2}-\mathrm{H}_{6}$ bond, which shrinks by $\sim 0.36$ to $\sim 0.38 \AA$ in the structure of the isomer 1 compared with the transition state. The $\mathrm{S}_{7}-\mathrm{H}_{6}$ bond length correspondingly increases by $\sim 0.37$ to $\sim 0.38 \AA$ along with isomerization reaction 2 which indicating a breaking of this chemical bond in the transition state. Inspection of the $\mathrm{N}_{2}-\mathrm{C}_{3}$ chemical bond lengths reveal changes from double to single bond character, with bond lengths increasing from 1.296$1.302 \AA$ to $1.345-1.354 \AA$ in the transition states. According to the geometrical parameters, dihedral angles for the isomerization reaction $\mathbf{2}$ indicate that the TS 
geometry is planar. At the B3LYP/aug-cc-pVTZ, M06-2x/aug-cc-pVTZ, and CBS-QB3 theoretical levels, the imaginary frequency characterized for the TS found are $1635.5 i, 1639.6 i$, and $1624.6 i \mathrm{~cm}^{-1}$, respectively.

Table 1. Reaction and activation parameters (energies, enthalpies, and Gibb's free energies) for the isomerization reactions at different levels of theory $(P=1$ atm). Energies (enthalpies and Gibb's free) are given in $\mathrm{kcal} \mathrm{mol}^{-1}$.

\begin{tabular}{|c|c|c|c|c|c|c|}
\hline \multirow[b]{2}{*}{ parameter } & \multicolumn{3}{|c|}{$\begin{array}{c}\text { Reaction 1 } \\
{[\text { isomer } 1 \rightarrow \text { isomer 2] }}\end{array}$} & \multicolumn{3}{|c|}{$\begin{array}{c}\text { Reaction 2 } \\
{[\text { isomer } 2 \rightarrow \text { isomer } 1]}\end{array}$} \\
\hline & B3LYP & M06-2x & CBS-QB3 & B3LYP & M06- $2 x$ & CBS-QB3 \\
\hline$\Delta E_{0 \mathrm{~K}}$ & 14.784 & 14.494 & 13.726 & -14.784 & -14.494 & -13.726 \\
\hline$\Delta H^{\circ}{ }_{298 \mathrm{~K}}$ & 15.020 & 14.187 & 14.003 & -15.020 & -14.187 & -14.003 \\
\hline$\Delta G^{\circ}{ }_{298 \mathrm{~K}}$ & 14.613 & 15.216 & 13.443 & -14.613 & -15.216 & -13.443 \\
\hline$\Delta E_{0 \mathrm{~K}}^{\dagger}$ & 43.681 & 44.738 & 43.407 & 28.897 & 30.244 & 29.681 \\
\hline$\Delta H^{\circ}{ }_{298 \mathrm{~K}}^{\dagger}$ & 43.579 & 44.547 & 43.345 & 28.559 & 30.360 & 29.342 \\
\hline$\Delta G^{\circ}{ }_{298 \mathrm{~K}}^{\dagger}$ & 43.740 & 45.218 & 43.337 & 29.127 & 30.003 & 29.895 \\
\hline
\end{tabular}

Table 2. Structural parameters for all stationary points involved in the isomerization reactions optimized at different levels of theory. (See Scheme 1 for atom labeling).

\begin{tabular}{|c|c|c|c|c|c|c|c|c|c|}
\hline \multirow{2}{*}{ parameter species } & \multicolumn{3}{|c|}{ B3LYP/aug-cc-pVTZ } & \multicolumn{3}{|c|}{ M06-2x/aug-cc-pVTZ } & \multicolumn{3}{|c|}{ CBS-QB3 } \\
\hline & isomer 1 & TS & isomer 2 & isomer 1 & TS & isomer 2 & isomer 1 & TS & isomer 2 \\
\hline$r\left(\mathrm{~N}_{1}-\mathrm{N}_{2}\right)$ & 1.374 & 1.381 & 1.391 & 1.367 & 1.373 & 1.382 & 1.376 & 1.381 & 1.393 \\
\hline$r\left(\mathrm{~N}_{2}-\mathrm{C}_{3}\right)$ & 1.351 & 1.317 & 1.299 & 1.345 & 1.311 & 1.296 & 1.354 & 1.319 & 1.301 \\
\hline$r\left(\mathrm{C}_{3}-\mathrm{N}_{4}\right)$ & 1.385 & 1.354 & 1.373 & 1.375 & 1.348 & 1.365 & 1.389 & 1.358 & 1.377 \\
\hline$r\left(\mathrm{~N}_{4}-\mathrm{C}_{5}\right)$ & 1.378 & 1.396 & 1.377 & 1.374 & 1.388 & 1.371 & 1.382 & 1.399 & 1.381 \\
\hline$r\left(\mathrm{~N}_{1}-\mathrm{C}_{5}\right)$ & 1.298 & 1.303 & 1.306 & 1.293 & 1.299 & 1.299 & 1.300 & 1.306 & 1.305 \\
\hline$r\left(\mathrm{~N}_{2}-\mathrm{H}_{6}\right)$ & 1.004 & 1.379 & - & 1.005 & 1.369 & - & 1.007 & 1.388 & - \\
\hline$r\left(\mathrm{C}_{3}-\mathrm{S}_{7}\right)$ & 1.665 & 1.721 & 1.761 & 1.662 & 1.716 & 1.751 & 1.666 & 1.723 & 1.763 \\
\hline$r\left(\mathrm{~S}_{7}-\mathrm{H}_{6}\right)$ & - & 1.727 & 1.345 & - & 1.713 & 1.340 & - & 1.722 & 1.343 \\
\hline$\angle \mathrm{H}_{6}-\mathrm{N}_{2}-\mathrm{C}_{3}$ & 125.31 & 82.08 & - & 125.04 & 81.17 & - & 125.16 & 81.85 & - \\
\hline$\angle \mathrm{N}_{2}-\mathrm{C}_{3}-\mathrm{S}_{7}$ & 130.87 & 109.76 & 128.00 & 131.20 & 110.19 & 128.66 & 130.86 & 109.74 & 128.12 \\
\hline$\angle \mathrm{C}_{3}-\mathrm{S}_{7}-\mathrm{H}_{6}$ & - & 61.78 & 92.98 & - & 61.15 & 92.77 & - & 61.97 & 92.92 \\
\hline$\varphi\left(\mathrm{H}_{6}-\mathrm{N}_{2}-\mathrm{C}_{3}-\mathrm{S}_{7}\right)$ & 0.0 & 0.0 & - & 0.0 & 0.0 & - & 0.0 & 0.0 & - \\
\hline$\varphi\left(\mathrm{H}_{6}-\mathrm{N}_{2}-\mathrm{C}_{3}-\mathrm{N}_{4}\right)$ & -180.0 & 180.0 & - & -180.0 & -180.0 & - & 179.98 & -180.0 & - \\
\hline$\varphi\left(\mathrm{N}_{2}-\mathrm{C}_{3}-\mathrm{S}_{7}-\mathrm{H}_{6}\right)$ & - & 0.0 & 0.0 & - & 0.0 & 0.0 & - & 0.0 & 0.0 \\
\hline$\varphi\left(\mathrm{N}_{1}-\mathrm{N}_{2}-\mathrm{C}_{3}-\mathrm{S}_{7}\right)$ & -180.0 & -180.0 & 180.0 & -180.0 & 180.0 & -180.0 & -180.0 & 180.0 & -180.0 \\
\hline
\end{tabular}

- Bond lengths are given in angstrom $(\AA)$; Bond angles and dihedral angles are in degrees $\left(^{\circ}\right)$.

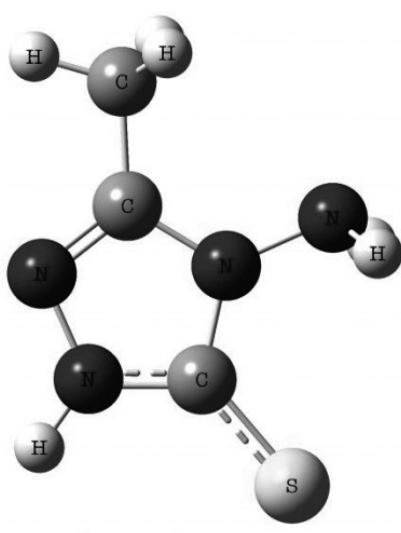

isomer 1

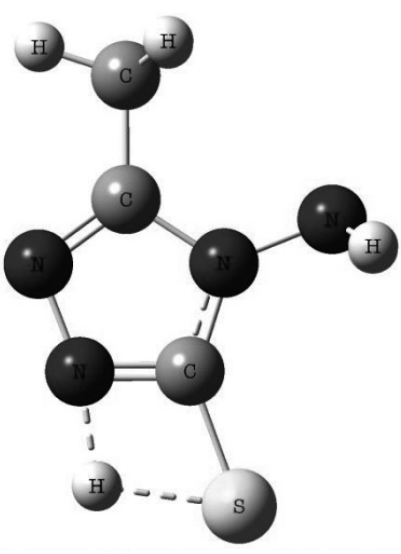

transition state

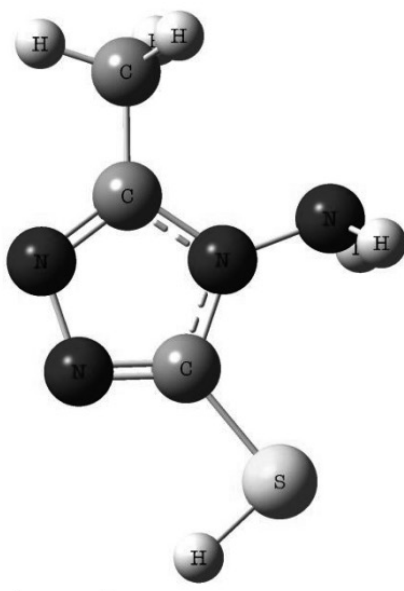

isomer 2

Fig.2. All stationary points are involved in the isomerization reactions $\mathbf{1}$ and $\mathbf{2}$ 
According to Hammond's postulate, the transition state structure would resemble the products more than the reactants [68]. This resemblance is usually quantified in terms of the position of the TS structure along the reaction coordinate, $n_{\mathrm{T}}$, as defined by [69]:

$$
n_{\mathrm{T}}=\frac{1}{2-\left(\Delta G^{\circ} / \Delta G^{\dagger}\right)}
$$

The $n_{\mathrm{T}}$ values for the induced isomerization reaction $\mathbf{2}$ is equal to $\sim 0.4$, while this value is equal to $\sim 0.6$ for reaction pathway $\mathbf{1}$. The isomerization reaction $\mathbf{1}$ is characterized by a transition state which is structurally closer to the isomer 2 than to the isomer 1 , and is expected therefore to be endoergic ( $\Delta G$ $>0$ ). Accordingly, the relationship between the earliness of the transition states and the $\Delta G$ values is very well observed

IRC reaction profile is shown in Fig. 3. IRC calculations demonstrated that the transition state structure connect the reactant (isomer 2) and product (isomer 1). The $\log A$ has been used to suggest the type of transition state according to Benson [70-72]. The transition state for the isomerization reaction has four-center structure.

\section{Kinetic parameters}

Kinetic rate constants for the isomerization reactions $\mathbf{1}$ and $\mathbf{2}$ are supplied in Table 3 at a pressure of 1 bar and $T=298 \mathrm{~K}$. Kinetics rate constants are the results of TST calculation performed using different quantum chemical data. Under atmospheric condition, rate constant for the reaction $\mathbf{2}$ is larger than that obtained for reaction $\mathbf{1}$, which is in line with a reduction of the activation

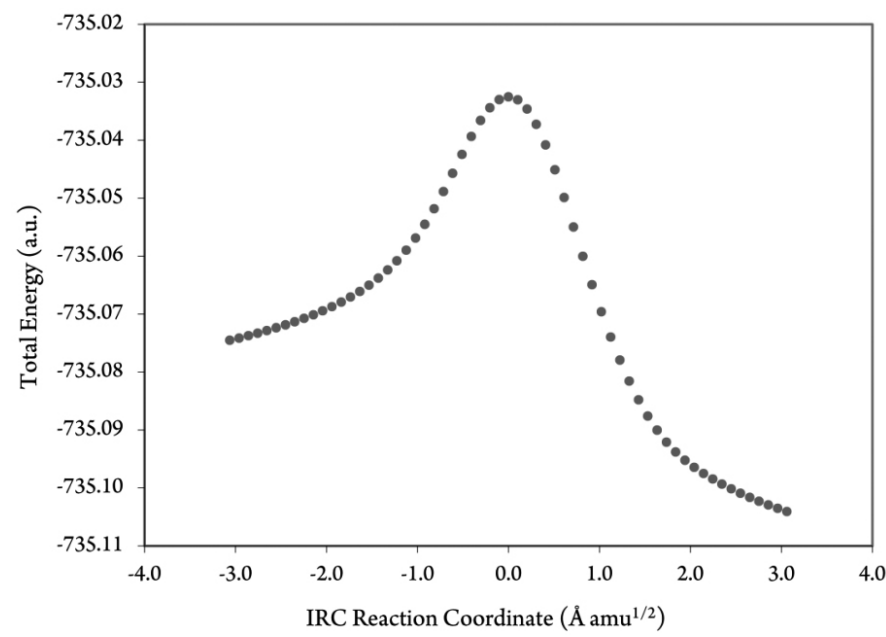

Fig.3. IRC reaction profile for the isomerization reactions at the B3LYP/6$31 \mathrm{G}^{* *}$ level of theory.

energy barrier by $13.73-14.78 \mathrm{kcal} \mathrm{mol}^{-1}$. As is to be expected, because of the involved positive energy barrier, the rate constant will increase gradually with increasing temperatures. At a pressure of $1 \mathrm{bar}$, the formation of the isomer 1 species will therefore clearly predominate over the formation of the isomer 2 species. These results indicate that reaction $\mathbf{2}$ is from both thermodynamic and kinetic viewpoints more favorable than the chemical reaction 1.

Table 3. The temperature-dependent kinetic rate constants for the studied reactions, tunneling corrections, and fitted modified Arrhenius parameters $\left[k=\mathrm{A} T^{n}\right.$ $\left.\exp \left(-E_{\mathrm{a}} / R T\right)\right]$ calculated using TST theory $(P=1$ bar, $T=298 \mathrm{~K})$ at different theoretical levels.

\begin{tabular}{|c|c|c|c|}
\hline $\begin{array}{ll}\text { Parameters } & \text { Methods } \\
\end{array}$ & B3LYP/aug-cc-pVTZ & M06-2x/aug-cc-pVTZ & CBS-QB3 \\
\hline \multicolumn{4}{|c|}{ Reaction 1 [isomer $1 \rightarrow$ isomer 2] } \\
\hline$k\left(\mathrm{~s}^{-1}\right)$ with Wigner tunneling factor & $1.98 \times 10^{-16}$ & $1.02 \times 10^{-17}$ & $5.45 \times 10^{-16}$ \\
\hline$A\left(\mathrm{~s}^{-1}\right)$ with Wigner tunneling factor & $6.61 \times 10^{12}$ & $3.89 \times 10^{12}$ & $8.95 \times 10^{12}$ \\
\hline$\kappa_{\text {wigner }}(T)$ & 3.60 & 3.46 & 3.51 \\
\hline$E_{\mathrm{a}}\left(\mathrm{kJ} \mathrm{mol}^{-1}\right)$ & 163.74 & 169.07 & 161.98 \\
\hline$k\left(\mathrm{~s}^{-1}\right)$ with Eckart tunneling factor & $4.50 \times 10^{-16}$ & $2.16 \times 10^{-17}$ & $1.30 \times 10^{-15}$ \\
\hline$A\left(\mathrm{~s}^{-1}\right)$ with Eckart tunneling factor & $1.76 \times 10^{0}$ & $1.39 \times 10^{1}$ & $1.01 \times 10^{0}$ \\
\hline$\kappa_{\text {Eckart }}(T)$ & 8.65 & 7.33 & 8.42 \\
\hline$E_{\mathrm{a}}\left(\mathrm{kJ} \mathrm{mol}^{-1}\right)$ & 147.37 & 154.13 & 145.02 \\
\hline \multicolumn{4}{|c|}{ Reaction 2 [isomer $2 \rightarrow$ isomer 1$]$} \\
\hline$k\left(\mathrm{~s}^{-1}\right)$ with Wigner tunneling factor & $6.36 \times 10^{-8}$ & $2.13 \times 10^{-9}$ & $1.88 \times 10^{-8}$ \\
\hline$A\left(\mathrm{~s}^{-1}\right)$ with Wigner tunneling factor & $1.04 \times 10^{14}$ & $5.74 \times 10^{13}$ & $1.34 \times 10^{14}$ \\
\hline$\kappa_{\text {wigner }}(T)$ & 3.40 & 3.23 & 3.28 \\
\hline$E_{\mathrm{a}}\left(\mathrm{kJ} \mathrm{mol}^{-1}\right)$ & 113.27 & 119.60 & 116.53 \\
\hline$k\left(\mathrm{~s}^{-1}\right)$ with Eckart tunneling factor & $5.57 \times 10^{-8}$ & $1.53 \times 10^{-9}$ & $1.62 \times 10^{-8}$ \\
\hline$A\left(\mathrm{~s}^{-1}\right)$ with Eckart tunneling factor & $4.76 \times 10^{9}$ & $9.43 \times 10^{9}$ & $5.86 \times 10^{9}$ \\
\hline$\kappa_{\text {Eckart }}(T)$ & 3.10 & 2.50 & 3.02 \\
\hline$E_{\mathrm{a}}\left(\mathrm{kJ} \mathrm{mol}^{-1}\right)$ & 108.86 & 116.37 & 112.13 \\
\hline
\end{tabular}


All obtained temperature-dependent TST rate constants and fitted modified Arrhenius parameters for the chemical reactions $\mathbf{1}$ and $\mathbf{2}$ are presented in Table 3. Detailed inspection of Table 3 shows that kinetic rate constants calculated at a pressure of 1.0 bar using the TST approaches in conjunction with the same energy profiles are positively dependent on the tunneling effect on the kinetic reaction rate at $T=298 \mathrm{~K}$. The associated Wigner and Eckart tunneling factors for favorable isomerization reaction [isomer $2 \rightarrow$ isomer 1 ] show that tunneling effects have an influence on the kinetic rate constant. Indeed, based on the computed energy profiles and vibrational frequencies, $\kappa(T)$ values related to the Wigner and Eckart tunneling ranging from 3.46 to 3.6, and 2.5 to 3.1, respectively, were found for TST calculations of the kinetic rate constants which characterize the studied pathways.

\section{Bond order analysis}

A more balanced measure of the extent of bond breaking or of bond forming along a chemical reaction pathway is provided by the concept of bond order $(B)$ which has been used to investigate the molecular mechanism of many chemica reactions $[45,73,74]$. In the present work, Wiberg bond indices [75] have been computed based on an NBO analysis [76]. There are several forming/breaking bond processes along the fragmentation process and the global nature of the isomerization reactions $\mathbf{1}$ and $\mathbf{2}$ can be monitored using the synchronicity $\left(S_{y}\right)$ index [77] which is defined as follows:

$$
S_{y}=1-\frac{\left[\sum_{i=1}^{n} \frac{\left|\delta B_{i}-\delta B_{a v}\right|}{\delta B_{a v}}\right]}{2 n-2}
$$

where $n$ is the number of bonds directly involved in the chemical process, $\delta B_{\mathrm{i}}$ is the relative variation of the bond index for a bond $i$ at the TS, and $\delta B_{\alpha v}$ is the average value in the change of bond orders. The synchronicity parameter $S$ varies between 0 and 1 , that with a value of $S=0$ indicating a fully asynchronic processes, whereas a value of $S_{y}=1$ shows on the contrary a fully concerted synchronic process [78].

Bond indices were calculated for the chemical bonds that are involved in the isomerization reaction, i.e. the $\mathrm{N}_{2}-\mathrm{H}_{6}, \mathrm{~N}_{2}-\mathrm{C}_{3}, \mathrm{C}_{3}-\mathrm{S}_{7}$, and $\mathrm{H}_{6}-\mathrm{S}_{7}$ bonds (see Scheme 1 for atom numbering). All other bonds remain practically unaltered. The calculated Wiberg bond indices $B$ for the reactant, transition state and product enable us to examine the reaction progress and to evaluate the position of the transition states between reactant and product (Table 4)

Reaction 1 leads to the cleavage of $\mathrm{N}_{2}-\mathrm{H}_{6}$ bond to yield product located at 13.73-14.49 $\mathrm{kcal} \mathrm{mol}^{-1}$ above the reactant at the studied theoretical levels. Transition state result from a simple elongation of breaking $\mathrm{N}_{2}-\mathrm{H}_{6}$ chemical bond and the simultaneous shrinkage of the $\mathrm{H}_{6}-\mathrm{S}_{7}$ distance as a result of forming the $\mathrm{H}_{6}-\mathrm{S}_{7}$ simple bond. The $\mathrm{N}_{2}-\mathrm{H}_{6}$ bond is elongated by $1.369-1.388$ $\AA$, and the $\mathrm{H}_{6}-\mathrm{S}_{7}$ bond formed is longer than the equilibrium bond length in isomer 2 species. Wiberg bond indices show that for the isomerization reaction 1 , the changes in the $\mathrm{C}_{3}-\mathrm{S}_{7}$ bond $(\% E V=70.37 \%)$ more progress than the $\mathrm{N}_{2}-\mathrm{H}$ bond breaking, the $\mathrm{H}_{6}-\mathrm{S}_{7}$ bond forming, and changes in the $\mathrm{N}_{2}$ $\mathrm{C}_{3}$ bond $(\% E V=55.09 \%)$, which are intermediate in the reaction coordinate $(\% E V=57.30 \%$ and $\% E V=51.28 \%$, respectively $)$. Less progress is observed in the $\mathrm{H}_{6}-\mathrm{S}_{7}$ simple bond formation. The synchronicity index for this reaction is equal to 0.933 , which indicates that the studied channel can be described as one-step and slightly asynchronous.

Table 4. Bond order analysis of the structures involved in the reaction pathways 1 and 2 at the CBS-QB3 [B3LYP/6-311G(2d,d,p)] level of theory.

\begin{tabular}{clllllll}
\hline \multirow{2}{*}{ Reaction } & & $\mathrm{N}_{2}-\mathrm{H}_{6}$ & $\mathrm{~N}_{2}-\mathrm{C}_{3}$ & $\mathrm{C}_{3}-\mathrm{S}_{7}$ & $\mathrm{H}_{6}-\mathrm{S}_{7}$ & $\delta B_{\mathrm{av}}$ & $S_{y}$ \\
\hline & & & & & & & \\
\hline \multirow{2}{*}{ Reaction 1 } & $B_{i}(\mathrm{R})$ & 0.7930 & 1.2051 & 1.5063 & 0.0015 & 0.5851 & 0.933 \\
& $B_{i}(\mathrm{TS})$ & 0.3422 & 1.4157 & 1.2071 & 0.4896 & & \\
& $B_{i}(\mathrm{P})$ & 0.0063 & 1.5863 & 1.0811 & 0.9533 & & \\
& $\% E V$ & 57.303 & 55.089 & 70.367 & 51.282 & & \\
[isomer 1 $\rightarrow$ isomer 2] & & & & & & & \\
& $B_{i}(\mathrm{R})$ & 0.0063 & 1.5863 & 1.0811 & 0.9533 & 0.4145 & 0.905 \\
& $B_{i}(\mathrm{TS})$ & 0.3422 & 1.4157 & 1.2071 & 0.4896 & & \\
Reaction 2 & $B_{i}(\mathrm{P})$ & 0.7930 & 1.2051 & 1.5063 & 0.0015 & & \\
& $\% E V$ & 42.697 & 44.753 & 29.633 & 48.718 & & \\
\hline
\end{tabular}

Wiberg bond indexes $\left(B_{i}\right), \%$ evolution through the reaction coordinate $(\% E V)$, average bond index variation $\left(\delta B_{a v}\right)$ and synchronicity parameter $\left(S_{\mathrm{y}}\right)$ are shown.

Reaction 2 leads to the cleavage of $\mathrm{H}_{6}-\mathrm{S}_{7}$ bond through TS to produce isomer 1, located at $13.73-14.78 \mathrm{kcal} \mathrm{mol}^{-1}$ below the reactant (isomer 2) at all levels of theory. Transition state results from a simple elongation of the breaking $\mathrm{H}_{6}-\mathrm{S}_{7}$ bond and the simultaneous shrinkage of $\mathrm{N}_{2}-\mathrm{H}_{6}$ due to the formation of $\mathrm{N}_{2}-\mathrm{H}_{6}$ simple bond. The $\mathrm{H}_{6}-\mathrm{S}_{7}$ bond is elongated by $1.713-1.728$

$\AA$, and the forming $\mathrm{N}_{2}-\mathrm{H}_{6}$ bond is longer than the equilibrium bond length. Moreover, in this reaction the evolution in the bond breaking of $\mathrm{H}_{6}-\mathrm{S}_{7}(48.72 \%)$ is more progress than the $\mathrm{N}-\mathrm{H}_{6}$ bond forming, and changes in the $\mathrm{N}_{2}-\mathrm{C}_{3}$ bond ( $\% E V=44.75 \%$ ). On the other hand, $\mathrm{N}_{2}-\mathrm{C}_{3}$ bondchanges from double to single bond.

Changes in electron distribution during the reaction can be studied by means of charges. NBO charges have been proved to be useful in this sense [79]. We report NBO charges for isomers $\mathbf{1}$ and $\mathbf{2}$ and transition state as well in Table 5, with atom numbering being the same as that given in Scheme 1 NBO charges analysis demonstrates as the reaction proceeds from reactant to transition state in the reactions $\mathbf{1}$ and $\mathbf{2}$, the following changes in partial charges occur as follows are presented in Table 5

- In reaction 1 [isomer $1 \rightarrow \mathrm{TS} \rightarrow$ isomer 2], the increase in positive charges $\delta^{+}$in carbon $\mathrm{C}_{3}(0.209)$ in the isomer 1 compared to 0.236 in TS as changes in the $\mathrm{C}_{3}-\mathrm{S}_{7}$ bond, an increase innegative charge $\delta^{-}$in sulfur $\mathrm{S}_{7}(-0.278)$ in the isomer 1 compared to -0.171 in TS.

- in reaction 2 [isomer $2 \rightarrow \mathrm{TS} \rightarrow$ isomer 1], the increase in positive charges $\delta^{+}$in hydrogen $\mathrm{H}_{6}(0.163)$ in the isomer 2 compared to 0.339 in TS as $\mathrm{H}_{6}-\mathrm{S}_{7}$ bond breaks and an increase in negative charge $\delta^{-}$in sulfur $\mathrm{S}_{7}(0.002)$ in the isomer 2 compared to -0.171 in TS. 
Table 5. NBO Charges of isomers 1 and $\mathbf{2}$ and transition state for the isomerization reactions at the CBS-QB3 level of theory.

\begin{tabular}{|c|c|c|c|}
\hline $\begin{array}{ll}\text { atom } & \text { species }\end{array}$ & isomer 1 & TS & isomer 2 \\
\hline $\mathrm{N}_{1}$ & -0.29929 & -0.28281 & -0.30919 \\
\hline $\mathrm{N}_{2}$ & -0.37732 & -0.41659 & -0.33800 \\
\hline $\mathrm{C}_{3}$ & 0.20894 & 0.23550 & 0.22425 \\
\hline $\mathrm{N}_{4}$ & -0.26303 & -0.26245 & -0.27314 \\
\hline $\mathrm{C}_{5}$ & 0.41712 & -0.61639 & 0.38982 \\
\hline $\mathrm{H}_{6}$ & 0.41887 & 0.33904 & 0.16253 \\
\hline $\mathrm{S}_{7}$ & -0.27833 & -0.17126 & 0.00145 \\
\hline
\end{tabular}

Compounds with resonance structures often have chemical bonds that are not easily described as single or double bonds. So, in this case, bond order indicates the type and strength of covalent bonds between atoms. Bond order between $\mathrm{N}_{1}$ and $\mathrm{C}_{5}$ of isomer $\mathbf{1}$ is 1.626 whereas bond order between same atoms $\left(\mathrm{N}_{1}-\mathrm{C}_{5}\right)$ of isomer 2 is 1.612 . The bond between $\mathrm{N}_{1}$ and $\mathrm{C}_{5}$ of isomer $\mathbf{1}$ shows more double bond character than the other resonance form of isomer 2 .
In contrast, bond order between $\mathrm{N}_{2}$ and $\mathrm{C}_{3}$ of isomer $\mathbf{1}$ is 1.205 and bond order between same atoms of isomer $\mathbf{2}$ is 1.586. As a result, it is obvious that there are two resonance forms for both isomers mentioned in Fig. 4 but contribution of some resonance forms is more than the other. Furthermore, dominant resonance structure is determined by electronic structure of substituent.

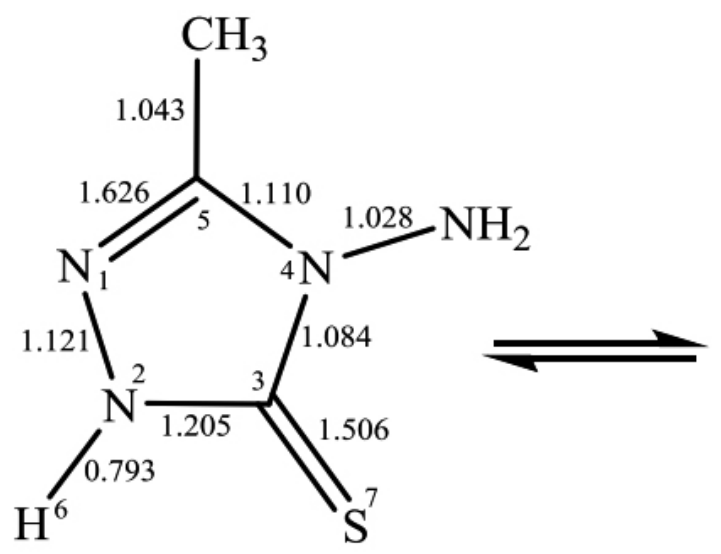

isomer 1

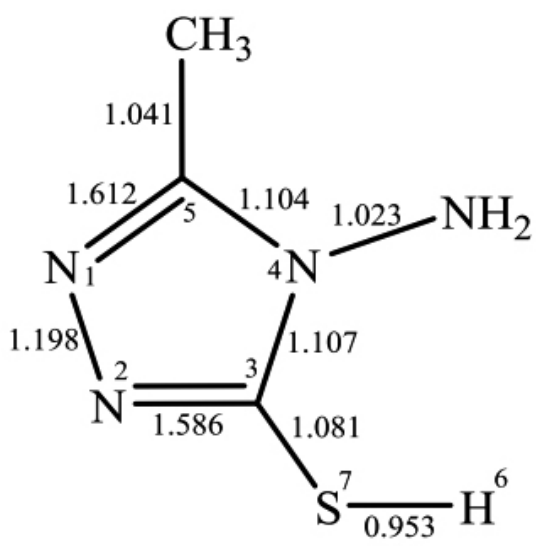

isomer 2

Fig.4. Bond orders for dominant resonance forms of 4-amino-5-methyl-2,4-dihydro-3H-1,2,4-triazole-3- thione

\section{Natural bond orbital analysis}

Natural bond orbital analysis is initially established as a way of quantifying resonance structure contributions to molecular systems. Delocalization of electron density among the filled (donor) Lewis type NBOs and the empty (acceptor) non-Lewis NBOs leads to transfer of occupancy from the localized NBOs of the idealized Lewis structure into the empty non-Lewis orbitals. It is referred to as "delocalization" correction to the zero-order natural Lewis structure to a stabilizing donor-acceptor interaction. The energies of these interactions can be estimated by the second-order perturbation theory [45]. Delocalization energy $\left(E_{2}\right)$ for each donor $\operatorname{NBO}(i)$ and acceptor $\operatorname{NBO}(j)$ is given by [80]:

$$
E_{2}=\Delta E_{i j}=q_{i}\left[\frac{F_{(i, j)}^{2}}{\varepsilon_{i}-\varepsilon_{j}}\right]
$$

where $\varepsilon_{i}$ and $\varepsilon_{i}$, represents diagonal matrix of orbital energies, $F_{(i, j)}$ denotes the off-diagonal NBO Fock matrix elements, and $q_{i}$ is the donor orbital occupancy.

Based on the B3LYP/6-311G(2d,d,p) optimized geometries and electronic structure characteristics of the isomers $\mathbf{1}$ and 2 , the NBO analysis of donoracceptor interactions (Table 6) revealed that the stabilization energies $\left(E_{2}\right)$ associated with the electronic delocalization from non-bonding sulfur LonePair $\left[\mathrm{LP}(\mathrm{e})_{\mathrm{S} 7}\right]$ to $\sigma^{*}{ }_{\mathrm{N} 2-\mathrm{C} 3}$ antibonding orbitals, increase from isomer $\mathbf{1}$ to isomer
2. The $\mathrm{LP}(\mathrm{e})_{\mathrm{S}} \rightarrow \sigma^{*}{ }^{2-\mathrm{C} 3}$ resonance energies for isomers $\mathbf{1}$ and $\mathbf{2}$ are 4.28 and $4.41 \mathrm{kcal} \mathrm{mol}^{-1}$, respectively. The occupancies of $\sigma{ }_{\mathrm{N} 2}{ }_{3}$ bonds increase in the following order: isomer $\mathbf{1}<$ isomer $\mathbf{2}$, while the occupancies of $\sigma^{*}{ }_{\mathrm{N} 2-\mathrm{C} 3}$ bonds increase in a parallel manner in the opposite order (Table 6). Furthermore, the NBO results revealed that by the increase of $\mathrm{LP}(\mathrm{e})_{\mathrm{S} 7} \rightarrow \sigma^{*}{ }^{*}$ resonance energy, energy barrier heights of the isomerization reaction $\left(\Delta E_{\mathrm{o}}\right)$ around fourmembered rings decrease from isomers $\mathbf{1}$ to $\mathbf{2}$.

Table 6. NBO occupancies and stabilization energies $\left(E_{2}\right)$ (in kcal mol $\left.{ }^{1}\right)$ characterizing isomers 1-2 and transition structures along the isomerization reactions based on the CBS-QB3 method.

\begin{tabular}{lccc}
\hline & species & \multicolumn{3}{c}{ B3LYP/6-311G(2d,d,p) } \\
\cline { 2 - 4 } parameters & isomer 1 & TS & isomer 2 \\
\hline Occupancies & & & \\
$\sigma_{\mathrm{N} 2-\mathrm{C} 3}$ & 1.98849 & 1.98628 & 1.98880 \\
$\sigma_{\mathrm{N} 2-\mathrm{C} 3}^{*}$ & 0.07279 & 0.03245 & 0.02650 \\
$\mathrm{LP}(\mathrm{e}) \mathrm{S}_{7}$ & 1.98710 & 1.98764 & 1.98712 \\
& & & \\
Stabilization energies $\left(E_{2}\right)$ & & & \\
$\mathrm{LP}(\mathrm{e}) \mathrm{S}_{7} \rightarrow \sigma_{\mathrm{N} 2-\mathrm{C} 3}^{*}$ & 4.28 & 0.99 & 4.41 \\
\hline
\end{tabular}




\section{CONCLUSIONS}

The isomerization kinetics of 4-amino-5-methyl-2,4-dihydro-3 $H$-1,2,4triazole-3-thione has been studied computationally in the gas phase at different DFT (B3LYP and M06-2x) as well as composite CBS-QB3 methods. The calculated energy profiles have been supplemented with calculations of kinetic rate constants under atmospheric condition by means of conventional transition state theory. The supplied data indicate that chemical reaction 2 [isomer $2 \rightarrow$ isomer 1] is from both thermodynamic and kinetic viewpoints more favorable than the chemical reactions 1 [isomer $1 \rightarrow$ isomer 2]. The transition states of these reactions correspond to planar four- membered cyclic structures. Analysis of these chemical pathways using synchronicity indices indicates one step and slightly asynchronous processes.

NBO analysis reveals that the stabilization energy associated from the electronic delocalization from the non-bonding lone-pair $\left[\mathrm{LP}(\mathrm{e})_{\mathrm{S} 7}\right]$ to $\sigma^{*}$ antibonding orbitals $\left[\mathrm{LP}(\mathrm{e})_{\mathrm{S} 7} \rightarrow \sigma^{*}{ }_{\mathrm{N} 2-\mathrm{C} 3}\right]$ increases from isomer 1 to isomer 2 . The LP(e) non-bonding lone-pair orbitals occupancies correspondingly increases in the following order: isomer $\mathbf{1}<$ isomer $\mathbf{2}$, while the occupancies of the $\sigma$ ${ }_{\mathrm{N} 2-\mathrm{C} 3}$ bonds increases in a parallel manner in the opposite order.

NBO charges analysis demonstrates that the $\mathrm{C}_{3}-\mathrm{S}_{7}$ bond is polarized in reaction 1 in the sense of $\mathrm{C}_{3}{ }^{\delta+}-\mathrm{S}_{7}{ }^{\delta-}$, while in the reaction 2 , the rate determining step revealed that the $\mathrm{H}_{6}-\mathrm{S}_{7}$ bond is highly polarized both in isomer 2 (as reactant) and TS structures in the sense of $\mathrm{H}_{6}^{{ }^{+}-}-\mathrm{S}_{7}{ }^{\delta-}$.

Analysis of the computed structures, bond orders and free energy profiles demonstrate that the isomerization reactions $\mathbf{1}$ and $\mathbf{2}$ satisfy Hammond's principle: the transition state for the chemical reaction $\mathbf{2}$ is structurally closer to the isomer 2 .

\section{REFERENCES}

[1] B. Namratha, and S. L. Gaonkar, Int. J. Pharm. 6, 73 (2014).

[2] S. Nekkanti, R. Tokala, and N. Shankaraiah, Curr. Med. Chem. 24, 2887 (2017).

[3]. J. K. Sahu, S. Ganguly, and A. Kaushik, Chin. J. Nat. Med. 11, 456 (2013).

[4] T. V. Ghochikyan, M. A. Samvelyan, A. S. Galstyan, and S. V. Grigoryan, Chem. Biol. 2, 8 (2016).

[5] G. A. Sandip, R. M. Suleman, and S. P. Vandana, Chem. Asian J. 6, 2696 (2011).

[6] P. Ratchanok, P. Veda, M. Prasit, C. Nantasenamat, S. Prachayasittikul, and S. Ruchirawat, Bioorg Med Chem. 23, 3472 (2015).

[7] R. Kaur, A. R. Dwivedi, B. Kumar, and V. Kumar, Anticancer. Agent. Med. Chem. 16, 465 (2016).

[8] A. N. Syed, M. Gurumurthy, J. C. Swarup, and P. Debashisha, Adv. Pharm. Res. 1, 26 (2010).

[9] J. Zhong, H. Aihong, L. Tao, H. Yan, L. Jianbing, and F. Jianxin, J. Organomet. Chem. 690, 1226 (2005).

[10]P. Elzbieta, and K. Iwona, II Farmaco 58, 423 (2003).

[11] S. Nadeem, and A. Waquar, Eur. J. Med. Chem. 45, 1536 (2010).

[12]J. Chen, X. Y. Sun, K. -Y. Chai, J. -S. Lee, M. S. Song, and Z. S. Quan, Bioorg. Med. Chem. 15, 6775 (2007).

[13] M. A. Ashraf, M. Hamdy, R. Abdel, S. A. Gamal-Eldien, and A. E. Mahamoud, Eur. J. Med. Chem. 44, 117 (2009).

[14]B. Tozkoparan, N. Gokhan, G. Aktay, E. Yesilada, and M. Ertan, Eur. J. Med. Chem. 35, 743 (2000).

[15] K. S. Bhat, B. Poojary, D. J. Prasad, P. Naik, and B. S. Holla, Eur. J. Med. Chem. 44, 5066 (2009).

[16]B. S. Holla, B. Veerendra, M. K. Shivananda, and B. Poojary, Eur. J. Med. Chem. 38, 759 (2003).

[17]C. Alkan, Y. Tek, and D. Kahraman, Turk. J. Chem. 35, 769 (2011).

[18]J. M. Vega-Pérez, I. Periñán, M. Argandoña, M. Vega-Holm, C. PaloNieto, E. Burgos- Morón, M. López-Lázaro, C. Vargas, J. J. Nieto, and F. Iglesias-Guerra, Eur. J. Med. Chem. 58, 591 (2012).

[19]J. Yao, J. Chen, Z. He, W. Sun, and W. Xu, Bioorg. Med. Chem. 20, 2923 (2012).

[20] C. S. Shantharam, V. D. M. Suyoga, R. Suhas, M. B. Sridhara, and G. D. Channe, Eur. J. Med. Chem. 60, 325 (2013).

[21] A. P. Keche, G. D. Hatnapure, R. H. Tale, A. H. Rodge, and V. M. Kamble, Bioorg. Med. Chem. Lett. 22, 6611 (2012).

[22] J. R. Burgeson, A. L. Moore, J. K. Boutilier, N. R. Cerruti, D. N. Gharaibeh, C. E. Lovejoy, S. M. Amberg, D. E. Hruby, S. R. Tyavanagimatt, R. D. Allen, and D. Daisar, Bioorg. Med. Chem. Lett. 22, 4263 (2012).

[23]B. Kocyigit-Kaymakcioglu, A. O. Celen, N. Tabanca, A. Ali, S.I. Khan, I. K. Khan, and D. E. Wedge, Molecules 18, 3562 (2013).
[24] S. Saha, D. Dhanasekaran, S. Chandraleka, N. Thajuddin, and A Panneerselvam, Adv. Biol. Res. 4, 224 (2010).

[25]R. Casasnovas, J. Frau, J. Ortega-castro, A. Salva, J. Donoso, and F. Munoz, Int. J. Quantum. Chem. 110, 323 (2010)

[26] J. A. Montgomery, Jr., M. J. Frisch, J. W. Ochterski, and G. A. Petersson, J. Chem. Phys. 110, 2822 (1999).

[27] J. W. Ochterski, G. A. Petersson, and J. A. Montgomery, Jr., J. Chem. Phys. 104, 2598 (1996).

[28]N. R. Nyden, and G. A. Petersson, J. Chem. Phys. 75, 1843 (1981).

[29] G. A. Petersson, A. Bennett, T. G. Tensfeld, M. A. Al-Laham, W. Shirley, and J. Mantzaris, J. Chem. Phys. 89, 2193 (1988).

[30] G. A. Petersson, and M. A. Al-Laham, J. Chem. Phys. 94, 6081 (1991

[31]. G. A. Petersson, A. K. Yee, and A. Bennett, J. Chem. Phys. 83, 5105 (1983).

[32] J. A. Montgomery, Jr., J. W. Ochterski, and G. A. Petersson, J. Chem. Phys 101, 5900 (1994).

[33] J. A. Montgomery, Jr., M. J. Frisch, J. W. Ochterski, and G. A. Petersson, J. Chem. Phys. 112, 6532 (2000).

[34] C. Lee, W. Yang, and R. G. Parr, Phys. Rev. B 37, 785 (1988).

[35]A. D. Becke, J. Chem. Phys. 98, 5648 (1993).

[36] Y. Zhao, and D. G. Truhlar, Acc. Chem. Res. 41, 157 (2008).

[37] T. H. Dunning, Jr., J. Chem. Phys. 90, 1007 (1989).

[38]H. Eyring, J. Chem. Phys. 3, 107 (1935).

[39]H. S. Johnston, Gas Phase Reaction Rate Theory, The Roland Press Co., New York, 1966.

[40]K. J. Laidler, Theories of Chemical Reaction Rates; McGraw-Hill: New York, 1969.

[41] R. E. Weston, and H. A. Schwartz, Chemical Kinetics, Prentice-Hall, New York, 1972.

[42]. D. Rapp, Statistical Mechanics, Holt, Reinhard, and Winston, New York, 1972.

[43]E. E. Nikitin, Theory of Elementary Atomic and Molecular Processes in Gases, Claredon Press, Oxford, 1974.

[44]I. W. M. Smith, Kinetics and Dynamics of Elementary Gas Reactions, Butterworths, London, 1980.

[45]A. E. Reed, R. B. Weinstock, and F. Weinhold, J. Chem. Phys. 83, 735 (1985).

[46] J. K. Badenhoop, and F. Weinhold, Int. J. Quantum. Chem. 72, 269 (1999

[47] Gaussian 09, Revision C.01, Gaussian, Inc., Wallingford CT, 2009.

[48]I. I. R. Dennington, T. Keith, J. Millam, K. Eppinnett, W. L. Hovell, and R. Gilliland, Gauss View, Version 3.09, Semichem, Inc.: Shawnee Mission, KS, 2003.

[49] Y. Zhao, and D. G. Truhlar, Theor. Chem. Acc. 120, 215 (2008)

[50]E. Zahedi, S. Shaabani, and A. Shiroudi, J. Phys. Chem. A 121, 8504 (2017).

[51] J. A. Sousa, P. P. Silva, A. E. H. Machado, M. H. M. Reis, L. L. Romanielo, and C. E. Hori, Braz. J. Chem. Eng. 30, 83 (2013).

[52]X. Li, and M. J. Frisch, J. Chem. Theory Comput. 2, 835 (2006).

[53]F. Fukui, J. Phys. Chem. 74, 4161 (1970).

[54]A. R. Oliaey, A. Shiroudi, E. Zahedi, and M. S. Deleuze, React. Kinet. Mech. Cat. 124, 27 (2018).

[55] S. Canneaux, F. Bohr, and E. Henon, J. Comput. Chem. 35, 82 (2013).

[56] M. D. Allendorf, T. M. Besmann, R. J. Kee, and M. T. Swihart, Chemical Vapor. Deposition: Precursors, Processes and Applications, $1^{\text {st }}$ edn., The Royal Society of Chemistry, UK, 2009.

[57]K. A. Holbrook, M. J. Pilling, and S. H. Robertson, Unimolecular Reactions, $2^{\text {nd }}$ edn., Wiley, Chichester, 1996.

[58]E. Wigner, J. Chem. Phys. 5, 720 (1937).

[59] E. P. Wigner, Z. Phys. Chem. B 19, 203 (1932).

[60]H. Eyring, S. H. Lin, and S. M. Lin, Basic Chemical Kinetics, Wiley, New York, 1980

[61] A. Shiroudi, E. Zahedi, A. R. Oliaey, and M. S. Deleuze, Chem. Phys 485-486, 140 (2017).

[62]H. Ostovari, E. Zahedi, I. Sarvi, and A. Shiroudi, Monatsh. Chem. 149, 1045 (2018).

[63]C. Eckart, Phys. Rev. 35, 1303 (1930).

[64]R. L. Brown, J. Res. Natl. Bur. Stand. 86, 357 (1981)

[65]A. Shiroudi, and M. S. Deleuze, Comput. Theor. Chem. 1074, 26 (2015).

[66] Computational chemistry comparison and benchmark database, precomputed vibrational scaling factors. http://cccbdb.nist.gov/vibscalejust. asp

[67]J. Troe, J. Chem. Phys. 66, 4758 (1977).

[68] G. S. Hammond, J. Am. Chem. Soc. 77, 334 (1953). 
[69] N. Agmon, and R. D. Levine, Chem. Phys. Lett. 52, 197 (1977).

[70] S. W. Benson, The Foundations of Chemical Kinetics, McGraw-Hill, New York, 1960.

[71]H. E. O’Neal, and S. W. Benson, S. J. Phys. Chem. 71, 2903 (1967).

[72] S. W. Benson, Thermochemical Kinetics, John Wiley \& Sons, McGrawHill, New York, 1960.

[73]G. Lendvay, J. Phys. Chem. 93, 4422 (1989).

[74] A. E. Reed, L. A. Curtiss, and F. Weinhold, Chem. Rev. 88, 899 (1988

[75]K. B. Wiberg, Tetrahedron 24, 1083 (1968).
[76] A. E. Reed, J. E. Carpenter, and F. Weinhold, NBO version 3.1, 2003

[77] A. Moyano, M. A. Periclas, and E. Valenti, J. Org. Chem. 54, 573 (1989).

[78] F. Rosas, R. M. Dominguez, M. Tosta, J. R. Mora, E. Marquez, T. Cordova, and G. Chuchani, J. Phys. Org. Chem. 23, 743 (2010).

[79]E. Marquez, J. R. Mora, T. Cordova, and G. Chuchani, J. Phys. Chem. A 113,2600 (2009).

[80] J. E. Carpenter, and F. Weinhold, J. Mol. Struct. (THEOCHEM) 169, 41 (1988). 